\title{
Aerobic Exercises on Type II Diabetic with Hypertension
}

\author{
S.S.Subramanian and P. Venkatesan \\ Professor Emeritus, Loyola College, Chennai-34, India. \\ DOI: http://dx.doi.org/10.13005/bbra/1886
}

(Received: 29 July 2015; accepted: 19 September 2015)

\begin{abstract}
Structured, Scientific means of Aerobic Exercises results in an improved Aerobic Power in Cardio respiratory system, within Muscle and Obesity, Blood pressure an improved glycaemic control. This study where the effects of Aerobic Exercises among Type II diabetes with Hypertension are analysed for their effects on obesity, hba1c and Blood Pressure. Methods: Being an Experimental Study Subjects, with known Type II DM and HT on Medication at random are allotted in two Groups. Duration of the study was six months from 2008 to 2013 . The study was conducted at Sree Balaji College of Physiotherapy, Chennai - 100. All the subjects waist circumferences, HBA1C, Blood Pressure, and Heart rate were measure once at the beginning and after at the completion of the study. Results: This Study reveals mean heart Rate reduced by $2 / \mathrm{mt}$, HBA1C by $.34 \%$, waist circumference by $2 \mathrm{~cm}$ and a mean reduction of systolic Blood Pressure by $3 \mathrm{~mm}$, diastolic by $2 \mathrm{~mm} / \mathrm{ng}$, among Aerobic subjects, while control subjects have shown insignificant outcome. Aerobic Exercises done regularly are effective on improving Glycaemic control, HTN and Obesity.
\end{abstract}

Key words: HTN -Hypertension, ACSM - American College of Sports Medicine, WHO -World Health Organization, HBA1C -Glycelated Haemoglobin.

Diabetes related healthcare cost Accounted for $11 \%$ of The Global healthcare Expenditure in adults in 2013 (Leahy2015). Hypertension is a major contributor to the cardiovascular morbidity and mortality in Industrialised Countries (Yusuf etal 2001). Among Urban Indian Population between 25-65 Years 22\% have HTN 41\% to be diabetic and 26\% are Smokers. (Purse - Hip 2011). Central Obesity Is Associated with Hypertension (Resin 1990) And Type II Diabetes (Ramachandran 2003).Obesity, Diabetes and Smoking Are Risk Factors for HTN in Most Countries (Sing 2000). WHO report in 2005 reports that India Lost 9 Billion US Dollar in 2015 due to premature death from Stroke, DM and heart Disease. Weight Loss due to a fat reduced diet, life style modifications and exercises results in a

\footnotetext{
* To whom all correspondence should be addressed.
}

sustained reduction in blood pressure (Wood 1991). With Aerobic Exercises (2004 Mayo Clinic) a reduction in blood pressure were recorded. Physical activities using Physioball is effective in improving glycaemic control among Type II Diabetics (Subramanian 2014).

\section{Background of this study}

This original research study aims to analyse the efficacy of Aerobic Exercises among Type II diabetic Indian Patients with Hypertension which is the first of its Kind, Shall strive to provide a Non Pharmacological intervention and cost effective management in the overall management of clinical trio of obesity, HTN and DM.

Inclusion Criteria

Type II Diabetic Patients with HT of both Sex.

\section{Exclusion Criteria}

Subjects with Cardiac, Nephro Neuro Complications. 


\section{Materials and Methodology}

Ethical clearance was obtained. This study was conducted between 2008-2013.Diabetic camps were conducted in May 2010. 120 subjects with known Type II diabetic were recruited in this study. Consent forms were obtained from all the participants. Using an experimental design all the subjects were allotted at random in two groups. Participants continued their duly prescribed Medication by their physician and daily routines.

Group I- No Specific Activities Were Prescribed (Control Group).

Group II- performed Aerobic Activities (Experimental Group).

Mercury sphygmomanometer was used in supine position to measure Blood Pressure. Best of two readings were taken at a 8 hours fasting state, two readings were taken at a fasting level, once prior to study, and after 6 months completion of study waist circumference at Xi phoid process was measured using an inch tape and recorded and a fasting HBA1c was measured twice once at the beginning, followed by resting heart rate was measured twice. Once prior to study and upon completion of the study.

Baseline Information of All the Subjects:

Waist Circumference $\rightarrow 97 \mathrm{~cm}$

Mean Age $\rightarrow 47$ Years

Smoking Habit $\rightarrow 30$ \%Known History of

Coronary Artery Disease $\rightarrow 47 \%$

\section{Procedure}

Group II Subjects Have Performed Stretching Of Muscles Such As

General Warm up, Pre Stretching, Aerobic warm up, Aerobic Activities and Cool Down.

Progression is made based on ACSM Guidelines.

\section{RESULTS AND DISCUSSION}

Among Aerobic subjects decrease in mean Heart Rate by 2/ minute, is similar to a study conducted by Salama Bweir etal 2009. Lowering of Heart rate with physical exercises implies an improved cardiac efficiency (Will more etal 1988).

Lowering of Blood Pressure among Aerobic subjects with a decrease of mean systolic by $3 \mathrm{~mm} / \mathrm{hg}$ and mean diastolic by $2 \mathrm{~mm} / \mathrm{hg}$. These findings are similar by another study conducted by Yun Kee etal 2010.

Economy of the muscle metabolism improves with Aerobic Training (Lewis etal 1985) also an improved health benefits and an improved endothelial function are reported with Aerobic Exercises (Green etal 2008).

Among Aerobic Subjects a reduction in mean HBA1C by .34\% is similar to findings of a study conducted by Ronald etal 2007. An improved glycaemic control with Aerobic Exercises are associated with decreased risk for Myocardial ischemic, stroke, peripheral Vascular disease (UKPD 1995) and a reduction of HBA1C is associated with improved regulation of GLUT4 (Banks etal 1992).

A Mean reduction in waist circumference among Aerobic Subjects by $2 \mathrm{cms}$ is similar to findings by Boule etal 2001 and hence these subjects benefit from Obesity related Cardio

Table 1. Mean Waist Circumference and paired ' $T$ ' Test of Group I and II

\begin{tabular}{lccccc}
\hline Group & Pre Meancm & Post Mean cm & SD & SE & P \\
\hline Group I & 97 & 97 & .89 & .14 & $\mathrm{P}>.1$. \\
Group II & 98 & 96 & 2.81 & .40 & $\mathrm{P}<.05 .$. \\
\hline
\end{tabular}

Non Significant

.. Significant

Table 2. Mean $\mathrm{HBA}_{1} \mathrm{C}$ and Paired 'T' Test of Group I and II

\begin{tabular}{lccccc}
\hline Group & Pre Meancm & Post Mean cm & SD & SE & P \\
\hline Group I & 7.72 & 8 & .28 & .04 & $\mathrm{P}>.1$. \\
Group II & 7.74 & 7.48 & .66 & .09 & $\mathrm{P}<.05$. \\
\hline
\end{tabular}

. Non Significant

.. Significant 
Table 3. Mean and Paired 'T' Test of Heart Rate of Group I and II

\begin{tabular}{lccccc}
\hline & Pre Mean Pre Minute & Post Mean Per Minute & SD & SE & P \\
\hline Group I & 84 & 85 & .4 & .004 & $>.1$. \\
Group II & 90 & 88 & 4.57 & .65 & $\mathrm{P}<.05 .$. \\
\hline
\end{tabular}

. Non Significant ... Significant

\begin{tabular}{llllll}
\hline & Mean & $\mathrm{mm} / \mathrm{ng}$ & $\mathrm{SD}$ & $\mathrm{SE}$ & $\mathrm{P}$ \\
\hline $\begin{array}{l}\text { Systolic B.P } \\
\text { Group I }\end{array}$ & $\begin{array}{l}\text { Pre } \\
\text { Post }\end{array}$ & $\begin{array}{l}122.56 \\
12.5\end{array}$ & 1.94 & .24 & $\mathrm{P}>.1$. \\
Group II & Pre & 122 & 5.09 & .72 & $\mathrm{P}<.05$. \\
& Post & 119 & & & \\
Diastolic B.P & & & & & \\
Group I & Pre & 82 & 1.67 & .24 & $\mathrm{P}>.1$. \\
Group II & Post & 83 & & & \\
& Pre & 81 & 5.74 & .81 & $\mathrm{P}<.05$. \\
& Post & 79 & & & \\
\hline
\end{tabular}

. Non Significant

Vascular complications among Type II DM are prudent conversion of Type II b fibres to Type II a, are major physiological mechanism with Aerobic Exercises (Saltin etal 1980).

\section{CONCLUSION}

Findings of this original research study with lowering of blood pressure, hba1c, obesity can be extended for prediabetic patients, children for further studies. Also detraining effects and larger sample size, comparing other modes of physical activities are recommended.

As shown in the findings of this research instead of just walking, concept of structured Aerobic components be spread among diabetic and hypertensive subjects for an improved benefits also a scientific mean of doing walking is facilitated.

\section{ACKNOWLEDGMENTS}

1. Management and staff ofLoyola College Department of Medical Lab Technology, Chennai - 34.

2. Management and Faculty of Sree Balaji College of Physiotherapy,Chennai - 100.

3. Medical Officer Volunteers And All The Subjects, SGS Clinic, Velachery, Chennai-42.

\section{REFERENCES}

1. Leahy J.L, Pathogenesis of Type II, Diabetic, American Medical Rej 2005; 36(3) 197-209.

2. Yusuf S, Reddy S, Ounpu S, Anand S, Global Burden of Cardio Vascular Disease Circulation 2001; 104: 2746 -53.

3. Dr.Thankachalam 2011 purse- rip project 20082011(8,000 Subjects Screened between 25-65 Years.

4. Resin E, Sodium and Obesity in the Pathogens of Hypertension A.M.J HT 1990; 3(1): 64-7.

5. Ramachandran, SA. Snehalatha C, Latha E, Metabolic Syndrome in Urban Asian Indian Adults; A population study using modified ATP III Criteria. Diabetes reference to clinical practice: 60:199-204.

6. Sing RB, SUHIL, Sing VP et al, Hypertension and stroke in Asia: Prevalence, Control and Strategies in developing countries for prevention J.HUM HTN 2000; 14: 749 - 63.

7. Wood P.D, Stephanic ML, Williams P.T, Haskell W.L, the effects of plasma lipo protein of a prudent weight reducing diet in obese Men and Women. NEJ Medicine: 1991; 325: 461-66.

8. Mayo Clinic, US Meta Analysis on 54 studies on Aerobic Training, 2004

9. Subramanian 2014 Effects of Physioball exercises on glycaemic control and quality life of Type II Diabetic Patients. Biosciences Biotechnology Research Asia, 2014; 11(1) P. No.325-328. 
2160 SUBRAMANIAN \& VENKATESAN, Biosci., Biotech. Res. Asia, Vol. 12(3), 2157-2160 (2015)

10. Salma Bweir, S. Mohamed; A.J. Jarrah, Abdul Majed Aalralty, Mikhled, Lisa and Bittel. Resistance Exercise Training Lowers HBA1C more than Aerobic Training in Adults with Type 2 Diabetes Diabetology and Metabolic Syndrome; 2009; 1(27):1-27.

11. Will More., J.H and Costill DH 1988 physiological basis of the conditioning process, $3^{\text {rd }}$ ed Dubuque, IA Brawn, 1988 .

12. Yankee Lee K, young whan sang, Nang., The effects of exercise program Anthropometric metabolic and Cardio Vascular parameters in Obese Children: Korean Circulation J 2010; 40(4): 179-184.

13. Levis SF, Shell PG and Taylor 1985, Role of Muscle Mass and mode of contraction in circulatory response to exercise. $\mathrm{J}$ of Applied physiology, 58: 146-151.

14. Green D.J, Maiorma, A, ordris coll G and Taylor. R., Effects of exercise training on endothelium derived nitric oxide function in humans. Journal of physiology 2004; 561: 1- 25.

15. Ronald J, sigal, Glemp, Kenny Normand G, George A and Wells, Effects of Aerobic training, resistance training or both on glycaemic control in Type II Diabetes. Annuals of Internal Medicine 2007; 147(6): 357-423.

16. UK prospective diabetes study 16, Review of 6 years Therapy of Type II Diabetes mellitus: Diabetes 1995: 44(11) 1249-58.

17. Banks, E. A Bozinick, Jr Yasselkis, N.Y.Kang, B.B and IVY, J.L, Muscle Glucose Transport, GLUT4 content and degree of Exercise Training in Obese 2 Ucker rates. MJ of Physiology, Endocrinology, Metabolism 1992; 263: E 1010 -E 1015.

18. Boule, N.G, Haddad, E and Kenny, G.P., Effects of Glycaemic Control and body Mass in Type 2 diabetes Mellitus: A Meta Analysis of Controlled Clinical Trials; J of the AM Medical Association, 2001; 286: 1218-1227.

19. WHO Report in on Inter Heart study of 52 countries about Economy of Health Care, 2005.

20. Saltin B, Lind Garde F, Lirrell, N, Eriksson K and Gad P., Metabolic effects of long term physical Training. Excerpt a Medical Amsterdam 1980; 9: 345-350. 